\title{
REPORT ON \\ DEPARTMENT OF ENERGY SUPPORT FOR OPERATIONS OF THE WMO/GAW QUALITY CONTROL/SCIENCE ACTIVITY CENTER FOR THE AMERICAS
}

\author{
B. B. Hicks (NOAA COTR) \\ Air Resources Laboratory \\ 1315 East West Highway \\ Silver Spring, MD 20910 \\ Reference DOE DE-AI02-94ER61753 \\ MAC000RR1B55WM
}

\section{SUMMARY.}

Global environmental monitoring is in sad shape. In particular, we lack a coherent system by which the quality of even the most basic environmental measurements can be assured. A fresh start has been made, with a new World Meteorological Organization's Global Atmosphere Watch (WMO/GAW) forming the framework for a nested network of regional and global observing stations. This new network subsumes and replaces the BAPMoN (Background Air Pollution Monitoring Network) and $\mathrm{GO}_{3} \mathrm{OS}$ (Global Ozone Observing System) activities of earlier decades.

A key to the success of GAW are three Quality Control Centers (QASACs). One of these is sponsored by Germany (covering Europe and Africa), and another by Japan (covering Asia and Oceania). A commitment has been made by NOAA to lead in the implementation and operation of a center to cover the Americas. It was initially estimated that a credible QASAC activity would require an annual budget of about $\$ 350 \mathrm{~K}$. It was agreed among the three leading US environmental agencies - EPA. NOAA and $\mathrm{DOE}$, that the cost would be equally distributed among them. In practice, a refined budget of $\$ 300 \mathrm{k}$ annually was finally adopted. The present report refers to the DOE-sponsored portion of the three-agency effort to promote an international program to ensure comparability and standardization of air quality data collected by independent national networks in the Americas. NOAA's Air Resources Laboratory has served as the organizing and administrative agent for the multi-agency activity. The actual work is centered in a single Quality Assurance/Science Activity Center, set up and run by the State University of New York at Albany, under the direction of Dr. Volker A. Mohnen.

The World Meteorological Organization's Global Atmosphere Watch serves two dominant purposes --

1. It is the international management tool under which the measurement programs of the global research-grade climate monitoring observatories are brought together, and

2. It is the mechanism by which the regional national atmospheric monitoring programs are integrated.

In practice, the first of these activities is essentially self-controlling. The scientists who make the measurements at the GAW global observatories are fundamentally driven by the need for data of the highest possible quality, and hence a formal quality control process is not a recognized necessity of the GAW global observatory program.

Regarding the second activity, it is well recognized that air quality and related atmospheric deposition associated with sources far upwind are potentially politically destabilizing. To ensure accurate identification of the pollution sources that contribute to local air pollution, in time enough to permit solutions to be negotiated and implemented, we must ensure that air quality data from any single nation can be 


\section{DISCLAIMER}

This report was prepared as an account of work sponsored by an agency of the United States Government. Neither the United States Government nor any agency thereof, nor any of their employees, makes any warranty, express or implied, or assumes any legal liability or responsibility for the accuracy, completeness, or usefulness of any information, apparatus, product, or process disclosed, or represents that its use would not infringe privately owned rights. Reference herein to any specific commercial product, process, or service by trade name, trademark, manufacturer, or otherwise does not necessarily constitute or imply its endorsement, recommendation, or favoring by the United States Government or any agency thereof. The views and opinions of authors expressed herein do not necessarily state or reflect those of the United States Government or any agency thereof. 


\section{DISCLAIMER}

Portions of this document may be illegible in electronic image products. Images are produced from the best available original document. 
compared directly with similar data from its neighbors. It is the goal of the Quality Assurance/Science Activity Centers (QA/SACs) of the GAW to provide this service. There are three such centers, one in each of the USA, Germany, and Japan. From the regional perspective, these have responsibility, respectively, for the Americas (North, Central, and South); Europe and Africa; and Asia, Australasia and Oceania. Each also has some global responsibilities. In the case of the QASAC for the Americas, the focus of the activity is on the world-wide quality control of all precipitation chemistry data, on UV- B and the provision of surface (and upper air) ozone levels for South America, and on the assurance of ozonesonde performance in the Americas.

In Japan, the QASAC has been institutionalized within the Japan Meteorological Agency with the identification of four fully supported staff members. In Germany, the QAVAC is now becoming operational, with long-term funding assured by the German Meteorological Service. In the USA, early discussion between representatives of EPA, DOE, and NOAA led to agreement that costs between the three agencies should be shared equally, with the total annual fimding level being $\$ 300 \mathrm{k}$. ARL was identified as the lead agency. A world-recognized group at the State University of New York was identified as the contractor.

With these three QASACs now operational there exists for the first time an opportunity to put in place rational and effective standard operating procedures worldwide. Participation of DOE has been crucial, because of DOE's long-standing involvement in air chemistry research in all aspects, and because of its leadership in matters concerning data quality as may influence the interpretation of consequences of fossil fuel combustion, etc.

Tropospheric ozone was selected as one of the initial focuses for the US QAVAC activity. Thus, the first effort of the new center was designing quality control procedures for aligning tropospheric ozone data collected at stations in the Americas, and on implementing quality assurance steps leading to an archiving function (WMO Publication No. 97 "Quality Assurance Project Plan (QAPjP) for Continuous Ground Based Ozone Measurements", 1996--NILU was designated as the World Data Center for Surface Ozone). It is intended that attention will be extended into the stratosphere at a later stage. As in all such focal areas, the goal is to ensure that data sets from separate regions of the world can be brought together seamlessly, and without loss of credibility. The QAVAC Americas has successfully completed a training workshop for GAW station operators in South America including scientists from the Southern Cone Ozone project (GEF funded WMO Stations). In addition the QA/SAC has initiated the first ozone sonde Intercomparison Experiment (JOSIE 1) at the newly designated WMO-World Calibration Facility for Ozone Sondes, Jülich Research Center, Germany. This was an essential first step towards improving the measurement accuracy/precision of ozone sondes in the troposphere and lower stratosphere.

Work of the QASAC (Americas) commenced in 1994. Funding from the EPA ceased in FY 1999. DOE support continued until 2001. Shortfalls have been made up from the research funds available to the Air Resources Laboratory of NOAA, until FY 2001. As of the time of this writing (early FY 2004), NOAA is bearing the entire cost of the program.

\section{INTRODUCTION}

In response to the WMO-Executive Council decision of July 1992 relating to the operation of the WMO "Global Atmosphere Watch - GAW" program, Quality Assurance/Science Activity Centers (QASACs) have been established for the geographic region Europe/Africa, the Americas, Australia and Asia in accordance with general guidelines developed for WMO in March of 1992 by a panel of experts (WMO GAW Report No. 80). Subsequently, a second meeting of experts - invited by WMO and hosted by the Institute for Atmospheric Environmental Research (IFU), Garmisch-Partenkirchen, December 7-11, 1992) - developed a set of specific guidelines and recommendations for the functions of these QAVSACs.

WMO-GAW (Global Atmosphere Watch) is a coordinated network of observing stations and related facilities whose purpose and long-term goal is to provide data, scientific assessments, and other 
information on changes in the chemical composition and related physical characteristics of the atmosphere from all parts of the globe. This information is required to improve understanding of the behavior of the atmosphere and its interactions with the oceans and the biosphere and to enable prediction of future states of the earth-atmosphere system.

The implementation of GAW, which began in 1989 as a consolidation of the former WMO atmospheric chemistry monitoring programs started in the 1950s, has been very successful. So far the program has established over 20 new regional and global stations in areas where data was sparse or non-existent, strengthened its calibration activities, data archival capabilities, and the quality of its data through the establishment of three Quality Assurance/Science Activity Centers and six World Data Centers, and improved the technical expertise within the program through technology transfer and capacity building efforts including sponsored workshops and training classes. Presently, $\sim 80$ member countries are participating in GAW's measurement program, (a quarter of them are establishing or operating global stations partly with support from other members or international organizations), which comprise a global network of precise and long term measurements. Many individuals have contributed to the development of the program, and, especially during the past three years, an enormous amount of work has been done by several leading scientists to ensure its continued progress. It is to the credit of these leaders that GAW has now become widely accepted as the basic monitoring system for atmospheric chemistry and physics.

The increases in tropospheric ozone, depletion of the stratospheric ozone layer, higher levels of acidity in rain, rising carbon dioxide and methane concentrations, and changes in the radiative balance of the earthatmosphere energy system--all reflect the increasing influence of human activity on the global

atmosphere, the life-support system of planet Earth. The impacts of these changes are many and serious. Atmospheric pollutants are affecting the health of human beings and animals, damaging vegetation, diminishing the quality of soil and water, accelerating the deterioration of stone, concrete, metals, and other materials, and altering the climate of the planet. It is these consequences and, more specifically, the need to understand the complex and interlinked mechanisms of atmospheric change, that provide the rationale for this WMO program, the Global Atmosphere Watch (GAW) and its associated Quality Assurance/Science Activity Centers (QA/SACS).

\section{HISTORICAL BACKGROUND.}

Numerous WMO meetings (and a flurry of reports) have emphasized that the global monitoring of air and precipitation chemistry is in sad shape. In particular, there has been no international process by which the quality of even the most basic environmental measurements can be assured. Major problems arose in the operations of so-called Regional Stations (measuring precipitation chemistry, atmospheric turbidity, and atmospheric particle loadings, for example); the data reported by research-grade global atmospheric observatories have not been so widely criticized. A fresh start is now being made, with a new Global Atmospheric Watch forming the framework for a nested network of refined regional and global observing stations. This new network subsumes and replaces the BAPMoN (Background Air Pollution Monitoring Network) activity of earlier decades.

A central goal of this activity is to permit data from individual national monitoring networks to be combined seamlessly, to provide the basis for sound regional environmental policy. To this end, a small number of internationally-recognized date Quality Assurance Centers is in place. One of these is sponsored by Germany (covering Europe and Africa), and another by Japan (covering Asia and Oceania). A commitment was made by the three leading environmental agericies of the USA - EPA, DOE, and NOAA - to lead in the setting up of a center to cover the Americas. This is among the highest priority of all activities currently being promoted by the WMO. Because of its historic leadership in studies of precipitation chemistry and atmospheric radioactivity, and because of its recent role in studies of atmospheric turbidity, the Air Resources Laboratory of NOAA accepted the responsibility to be the lead organization for setting up the QAVSAC for the Americas. 


\section{SPECIFIC OBJECTIVE.}

As a formal activity of the World Meteorological Organization's Global Atmosphere Watch, to provide, through agency collaboration, a center of excellence in the United States that would impose quality assurance techniques on data collected by national air and precipitation quality networks operating in the Americas (north, south, and central).

\section{PRODUCT.}

The final product of this activity will be regional data sets created by combining observations made in different nations using a variety of sampling methodologies that previously did not share common quality guidelines.

\section{APPROACH.}

The WMO has adopted a scheme in which three quality assurance centers will deal with data intercomparability problems in three major regions of the world - North and South America; Europe and Africa; and Asia and Oceania. The QA Center for the Americas has special focus on surface ozone, airborne radioactivity, aerosol optical depth, and precipitation chemistry. The QA center for the Americas was initially agreed to be funded jointly by DOE, EPA and NOAA. In recent years, support from EPA and DOE has evaporated. The activity is currently being continued under sponsorship solely of NOAA.

\section{PROGRAM OVERSIGHT.}

The QASACS receive direction and advice from the scientific community and interact with it through three formal mechanisms:

- The WMO Executive Council Panel/CASWG on Environmental Pollution and Atmospheric Chemistry (EC Panel). The specification and prioritization of science and science policy driven objectives are developed under the guidance of the WMO EC panel and with the support of the QAVSACs.

- International Scientific Programs in Atmospheric Chemistry and Aerosols. At present primary examples of these programs include the International Global Atmospheric Chemistry (IGAC) Program and the International Geosphere Biosphere Program (IGBP).

- Science and Technology Advisory Panel. In addition, to enhance interactions between the QA/SACs and the scientific community, each QAVSAC has a Science and Technical Advisory Panel (STAP) to provide advice on matters concerned with site selection, instrumentation selection, instrument calibration, auditing procedures, etc.

It was initially perceived that this commitment would enable continuation of the Quality Assurance/Science Activity Center for the Americas, dedicated to the need to impose credible and defensible standards on atmospheric environmental data collected in the Americas region of operations of the Global Atmosphere Watch of the World Meteorological Organization. It was planned that the overall activity would be made up of equal contributions from three agencies: DOE, EPA and NOAA.

\section{DESCRIPTION/SPECIFICATIONS/WORK STATEMENT}

The GAW represents an international effort of unprecedented complexity in the field of environmental measurement and assessment. Under the guidance of the EC/CAS, OSG and the active support of the QA/SACs, GAW is trying to make state of the science measurernents for a large number of mostly lowconcentration chemical and physical constituents of the atmosphere at levels extending from the surface to the stratosphere and at some of the most difficult locations on Earth. 
The QA/SACs must continue to strive to improve the quality, timeliness and completeness of GAW data, and to find broader application by the scientific community and in the countries concerned.

The QASAC for "The Americas" is an integral and essential part of the GAW program and participates to the maximum extent possible - in the overall core activities of GAW. These are:

- To acquire and distribute data of high and known quality - through the establishment of consistent and uniform quality control procedures and the development of global data exchange capabilities through the use of Internet and other international networks.

- To build up GAW's central calibration facilities and expand the support base - by enlisting the support of the world's best researchers and institutes in GAW leadership and program activities, and by working closely with the NMSs to support and embed GAW activities within their organizations and nations.

- To improve and expand the measurement network - by stabilizing operations at the present stations, by selectively extending the measurement capabilities and adding stations in targeted biomes and regions of the world with sparse or no coverage, by continued efforts at capacity building, and by harmonizing the global and regional components among GAW participants and GAW partners (e.g. EMEP).

- To expand the user base for GAW data - by proactive outreach to the scientific community, by making GAW data products more readily and easily available, and through increased efforts to support modeling, applications and scientific assessments which rely centrally on GAW data.

- To evolve GAW into a three-dimensional quality assured global observation network - through the integration of surface-based, aircraft, satellite and other remote sensing observations, and the improvement of the GAW network, with the goal of establishing a quasi-real-time monitoring capability.

The spectrum of parameters to be quality assured by QA/SACs within GAW is extremely broad. Given the size and complexity of the task, the implementation of the program can only be accomplished in a stepwise fashion. The QAVAC's responsibilities include the following elements/activities:

- Because ozone plays a central role in most of the key physical, chemical, and radiative processes in the troposphere, the improvement of tropospheric ozone measurements, especially their vertical distribution and quality, is of high priority. Although GAW total ozone measurements have been of high quality for several years, it is of great importance to maintain the effectiveness of this network and to ensure that satellite measurements are incorporated in current GAW ozone evaluations.

This will continue to be the QAVSAC activity of highest priority in the coming years. (See Appendix $V$ for an update on satellite integration.)

- Among the greenhouse gases and long-lived species $\mathrm{CO}_{2}$ has the longest record of measurement. The $\mathrm{CO}_{2}$ program is now well under control and constitutes a model of what the programs of other GAW components are expected to achieve. One of the highest priorities to emerge in recent $\mathrm{CO}_{2}$ studies is the attempt to infer sources and sinks of $\mathrm{CO}_{2}$ from measured concentration differences in space and time. Measurements of $\mathrm{CH}_{4}, \mathrm{~N}_{2} \mathrm{O}$, and CFCs have not yet reached the same quality level as practiced for $\mathrm{CO}_{2}$. Programs relating to these gases largely rely on the IGAC program and are not yet widely implemented at GAW sites. QASAC needs to focus its attention on these issues.

- Short-lived reactive chemical species that control the lifetimes of greenhouse gases must be measured at a small number of well-located and maintained global GAW stations where more complete sets of long-term measurements can be made in order to understand the effects of 
these species on atmospheric processes and behavior. Highest priority will be given to completing the operational carbon monoxide program and to developing the monitoring of volatile organic compounds (VOCs) and lower priorities to the development of programs for $\mathrm{NO}_{\mathrm{x}}$ and, especially, $\mathrm{SO}_{2}$.

- Measurements of precipitation chemistry and wet deposition have been, and continue to be, a high priority in most regions of the world, largely due to concerns about long range transport, acidification and eutrophication, and biogeochemical cycling. While the measurement methods are well-known and well-developed in some countries, they are poor and inconsistent in others. The QAVAC must now focus on upgrading the precipitation chemistry measurement system to a higher level of consistency and quality. As well, consideration must be given to expanding the program from wet deposition alone to air-surface exchange, particularly for $\mathrm{CO}_{2}$, methane and other greenhouse gases. The QA for precipitation chemistry will retain its high priority as an essential QAVSAC activity.

- Operational GAW measurements of UV-B, aerosols, and optical depth are still in the developmental phase. Though such measurements are made at some GAW sites, there has not been enough experience with measuring methods and quality assurance requirements to produce international agreement about common procedures. Nevertheless, the work of the different expert groups and the related research and test programs are of greát importance and will be rigorously pursued by QA/SAC so that these parameters can be measured at all global GAW sites at the earliest feasible date.

- The measurement of natural radioactivity $\left(\mathrm{Be},{ }^{85} \mathrm{Kr},{ }^{222} \mathrm{Rn}\right.$ and $\left.{ }^{210} \mathrm{~Pb}\right)$ can provide valuable insight into the local and regional transport mechanisms in support of the assessments of other measurements made at global sites. While the sampling and analytical technology is available, it is not currently implemented at many GAW sites. However, QAVSAC stands ready to implement radioactivity measurement whenever authorized by GAW.

- With the exception of UV, QASAC will put no emphasis on a separate quality assuring program for radiation. Radiation measurement activities must largely rely on the WWW and the WCRP/BSRN program of WMO. Therefore, QA/SAC will cooperate with these international programs but not implement separate QA/QC procedures.

Scientists trained and educated in atmospheric chemistry are in limited supply, and the availability of such scientists in Central and South America is particularly acute. Training and education, especially within the countries that have committed to maintain and operate GAW sites, are therefore critical to the program's long-term success.

GAW-specific education and training must be an integral part of the QA component and should be regional in character. Short-term training and education should focus on producing qualified GAW personnel for the development, implementation, and operation of a global station. In the last three years, several regional workshops devoted to this purpose were organized by the QAVACs. Further training and workshops will be carried out regularly by QAVSAC in close cooperation with WMO and where appropriate with IGAC-ACEED, with the highest priority being given to personnel of global stations and associated laboratories. Training activities for scientific and technical personnel include initial short courses, secondment training programs, annual meetings of station personnel, system audits and expert visits to provide feedback on the station's performance, and twinning.

\section{ACCOMPLISHMENTS.}

A major meeting of representatives of the three WMO Quality Assurance Centers was hosted by the QA center Europe/Africa at Garmisch-Partenkirchen, Germany, in March 1995. At this meeting it was 
announced that Japan will host the third of the centers, so completing the global coverage intended by WMO.

The QA plan prepared under this project for low-level ozone was transmitted to the World Health Organization for their consideration. WHO is installing an array of ozone monitors in South America, much in line with the proposal of the WMO. The WHO stations will be mainly in populated areas; the WMO stations will be at remote locations. If present plans come to fruition, both network operations will share common Quality Control and Assurance protocols, ensuring compatibility of data obtained.

Agreement was reached to ensure the continued U.S. maintenance of the WMO Precipitation Chemistry archive.

\section{Initial Activities.}

The purpose and long term goal of the Global Atmosphere Watch (GAW) is to provide data, scientific assessments and other information on the atmospheric chemical composition and related physical characteristics of the background atmosphere from all parts of the globe. The information obtained is required to improve understanding of the behavior of the atmosphere and its interactions with the oceans and the biosphere, and to enable prediction of the future states of the earth system. The Global Atmosphere Watch (GAW) is a coordinated system of networks of observing stations, facilities, and arrangements, encompassing the many measurement programs devoted to the investigation of the changing global atmosphere.

National and International policy decisions affecting the environment in the 21 st century will rely heavily on scientific data gathered through GAW. The need for better data on the global atmosphere is driven by both scientific and policy considerations. In practice, there is no strong societal incentive to resolve scientific uncertainties unless there is a policy issue at stake, and it is mostly when scientific uncertainties and policy requirements coincide that the need for new data is strongest. A sequence of steps then follows, leading to the selection of appropriate methods, through the design of appropriate quality control and assurance steps, and eventually to the provision of the desired data.

The WMO Quality Assurance/Science Activity Centers (QASACs) are established in accordance with general guidelines developed for WMO by a panel of experts (WMO CAW Report No. 80). A second meeting of experts developed a set of specific guidelines and recommendations for the functions and implementation of these QAVSACS.

It was initially estimated that a credible activity would require an annual budget of about $\$ 350 \mathrm{k}$. After discussions with representatives of each of the three U.S. agencies most directly involved: EPA, DOE, and NOAA, it was decided to share the cost among these agencies and to locate a contractor to serve as in the QAVSAC role, to oversee those existing quality assurance programs that are working well, and to put in place new programs as needed to ensure high quality data from GAW.

Precipitation chemistry, atmospheric radioactivity, and surface ozone were identified as subjects for immediate attention by the new QASSAC (Americas). In each case, the initial focus for the QASSAC would be on designing quality control procedures for aligning relevant data collected at stations in the Americas, and on implementing quality assurance steps leading to an archiving function. It was anticipated that the list of topics being addressed by the QA/SAC (Americas) would be expanded as the program continues.

Major initial work (starting in FY 1994) took place on two fronts, as follows.

(a) Contracting. The formal process for selection and sponsoring a lead organization involved a formal announcement of the program in the Commerce Business Daily, review of options available, and finally identification and selection of the State University of New York at Albany as the sole-source contractor. This selection was in line with the identification by the World Meteorological Organization of centers of 
excellence at SUNY/Albany and at the Fraunhofer Institute at Garmisch/Partenkirchen, Germany, as the two key institutes to start the global quality assurance program that is being set up.

The QAVSAC for Europe and Africa was then already operational, at the Fraunhofer Institute. The WMO now formally recognizes Garmisch and Albany as its first two QAVACs. Subsequently, the Japanese government has set up a third QA/SAC, to cover Asia and Oceania.

(b) Organizational. Specific steps were taken to straighten out several activities on an international basis.

Aerosol Optical Depth and Turbidity. A major international workshop was conducted at Silver Spring, Maryland, in December, 1993. This meeting resulted in the identification of a new Center of Excellence in Aerosol Optical Depth and Sunphotometry, located in Switzerland. This Center will be operating in close cooperation with the QASACs for Europe and the Americas, as new instrumentation is developed and distributed to a small number of global stations for a quality control testing program.

Ozone. Three areas of activity were identified, and progress was started on all.

For surface ozone, there was ongoing debate about the susceptibility of UV-absorption monitors to contamination by other chemicals. Problems were first identified in coastal areas, and new areas of concern subsequently became apparent. This topic was watched and evaluated as new scientific evidence became available. A focus for concern was the plan for a large surface ozone network in South America, where surface ozone data continue to be rare.

For radiosondes, the German national Laboratory at Julich accepted the challenge to provide an international calibration facility. Work was started (as an activity of the QASAC of the Americas) to generate operational guidance documentation and standard operating procedures for ozone radiosondes.

For Dobson/Brewer instrumentation, work was initiated with the ozone data center in Toronto to ensure and promote improved data intercomparability. This part of the operation is now well organized, and little additional activity is seen as being necessary.

Ultraviolet Radiation. A major international meeting was conducted in June, 1994, in Switzerland, at which an international steering committee for UV-B measurement was proposed. This committee is now active. In parallel with this international activity, a US cross-agency program was developed under the auspices of the US Global Change Research Program. Both activities recognized and endorsed a new UV calibration facility in Boulder, Colorado, as a mechanism to link operational needs for quality control of many instruments of different kinds with the intense but limited calibration capabilities of the US National Institute for Standards and Technology. This activity continues to be overseen and promoted by the QASAC of the Americas.

Precipitation Chemistry. The US has carried the historic burden of responsibility for the quality of the world's precipitation chemistry data base. During the 1990s, it became apparent that analytical problems in many countries are not being addressed adequately, and that attention by the QASAC of the Americas is warranted. The QAVSAC has succeeded in unifying the systems used globallyt for data quality assurance and archiving. Routine comparisons of analyzing laboratories are now conducted, annually. Recently, the East Asia Network (EANet) has been added to the GAW fold, throughb the activities and intervention of the QASAC.

Atmospheric Radioactivity. The DOE Environmental Measurements Laboratory in New York accepted a role as a quality control center of excellence for WMO/GAW measurements of atmospheric radioactivity. This activity is coordinated through the QASAC for the Americas. 


\section{Interactions with Data Centers.}

The QAVSACs are an integral part of a tripartite structure - GAW sites, QA/SACS and Data Centers. The activities of the QA/SACs are loosely divided into "network-wide" and "center-specific" tasks. The "center-specific" tasks can again be subdivided into those associated primarily with data flow, those associated primarily with quality assurance support, and those designed to ensure affective communication and dissemination of information between the various partners.

\section{a) Network-wide}

The Quality Assurance/Science Activity Centers have the responsibility for developing and administering the GAW-QAVQC program which includes the preparation of appropriate QA plans for all measurement components of GAW. It is the general philosophy of GAW that all countries and all organizations will abide by the procedures and methodologies sat forth in the GAW Quality Assurance Plan so that conclusions drawn from the GAW data base will be based on data of consistent and known quality. The fundamental concept in this approach is that WMO carries the overall responsibility for all GAW data and for an individual site operator from a particular country to be supplier to the GAW program, certain standardized QC procedures must be followed uniformly. It is not intended to interfere with programs that are already working well, but to extend the experience of these programs to other topical areas that are currently seen as being vulnerable.

Network-wide activities are related to the operations of the QAVSACs, which are conceived as forming a closely linked structure with minimum duplication and close coordination of activities. Many of the activities which are described are the same in all centers, but focussed on a different group of sites. Any activities concerned with the development of specific products which are applied across the network (QA routines, archiving software, communications facilities) should be coordinated by one of the QA/SACs in close cooperation with the others. A system should be developed for close coordination and networking between centers. Thus responsibility should be allocated for the following activities:

- General networking and information exchange. All the Information described under the center-specific functions must be passed on to the other QA/SACS to ensure maximum benefit to all network participants. In many cases joint activities (workshops, newsletter, etc.) will be more appropriate than single-center activities.

Avoidance of duplication. Procedures should be developed to ensure mutual coordination of all development activities and to minimize duplication across the network.

- Assurance of parsimony. Care must be taken to guard against unwarranted or unnecessary attention to detail in any specific area of concern. A balance measurement program is desired, without any part being of unacceptably low or unnecessarily high quality. Efforts to continually improve data quality should be moderated by consideration of why the data are being obtained.

An essential task of the QAVSACs is the evaluation and verification of GAW data. The following information should be supplied to the designated QAVAC by the individual sites: (1) Measurement parameters; (2) Identification of the standard and the history of the standards used; (3) Results of calibration; (4) Measurement of variance or other indicator(s) of instrument performance (as specified by the standard operating procedures - e.g., control charts); (5) Equipment used; (6) Changes in site conditions; (7) Results of QA experiments performed at the sites.

The QA/SACs then perform QA/QC functions using criteria as outlined in the Quality Assurance Project Plan (QAPJP) which defines the data quality objectives (DQOs) for each GAW measurement component. In the light of the information provided to the QAVSACS, the data can be:

- transmitted to the appropriate data center as designated by WMO, or 
- returned to the site with questions regarding the data quality. (In collaboration with the site the data would then be reviewed. The final status (flags) are assigned by the site and the data-returned to the QASAC for transmittal to the appropriate data center.)

In order to ensure that there is no undue delay in transmittal of data to the Data Center(s), the QAVSACs are required to forward the data within an agreed time; if necessary with an appropriate flag indicating the data have not been adequately reviewed. The flagging process should cover problems relating to estimation of accuracy, precision, data completeness, representativeness, plausibility, procedural departures, audits, calibrations, interferences, time and space resolution, and the availability (or otherwise) of supporting observations.

After consideration of identified problems, additional tests on data may be necessary; these should be sorted out by the QASAC and the appropriate site operators.

\section{b) Center specific}

From the communications point of view, the most important aspect of data flow is the development of methodologies to facilitate the uninterrupted and reliable recording and transfer of data from the site, through the QAVSAC, to the data center. This includes:

- Defining and reaching agreement on a standardized data format;

- Developing (identifying within the network) archiving software for recording of data, which can be made available to sites;

- Developing software for testing the acceptability of data sets and repackaging data into component parts for transfer to the data centers;

- Developing a schedule for transfer of data.

Quality assurance support activities include:

- Developing the schedule for quality control activities (site visits, performance and systems-audits, etc.).

- Designing and conducting of experiments, either to resolve discrepancies observed during review of data from individual sites, or in response to a request from a data center (to resolve discrepancies between data and different regions).

- Promoting close links between sites with more experience in the type of measurements required, and those where increased training is desirable. (Such twinning arrangements are likely to be the most effective means of ensuring rapid upgrading of all measurements in the network to the same high standard.)

- Reviewing site locations periodically, (a) to ensure that the locations are sufficient to meet the requirements for any new scientific objectives included in the program, and b) to identify possible gaps resulting from fundamental changes in site locations identified during routine quality assurance checks.

- Allotting station performance ratings according to well-defined definitions, and recommending removal of a station from the network if data are continually found to be of poor quality.

- Developing procedures for raising awareness of technological changes and ensuring efficient technology transfer within the network.

- Conducting instrument comparison workshops, and promoting improvements in instrumentation. 
- Establishing research ties with those members of the scientific community who are potential users of the GAW data.

\section{QA/SAC COOPERATION WITH INTERNATIONAL PROGRAMS.}

QA/SAC continues its contacts with the international scientific community. Many significant QASAC activities depend on collaboration, resource sharing, and interaction with a range of other international initiatives:

- Ozone-related matters: IAMAS/International Ozone Commission and International Radiation Commission, CEOS-IGOS, NDSC-SPARC, IGBP/IGAC, FCC/INC, UNEP, WHO, IGAC-GLONET, NASA SHADOZ and NASA SAGE III

- Air pollution related matters: CIMO, WCRP, GCOS, IGBP/IGAC, FCC/INC, UNEP/GEMS

- Transport, transformation, and deposition: ICSU/IAMAS, IGBP/IGAC, MEDPOL

- Education and training: IGBP START, IGAC-ACE ${ }^{E D}$

- Regional aspects: International Oceanographic Commission/GESAMP, EMEP, AMAP, ETEX

GAW is a component of GCOS. The role of GAW within GCOS is specified in detail in WMO/TD Report No. 720. Collaboration with other international programs with complementary and compatible objectives should be encouraged. In cooperation with UNEP and ECE, for example, efforts should be made to locate ecosystem studies at or near global GAW stations and to involve Members and stations in integrated monitoring activities. Collaboration with ICSU and IGBP involving the use of and access to geophysical data would also be helpful because both programs are operating global data bases. Within the framework of the Environmental Emergency Response Project, cooperation with IAEA and the CEC is necessary.

Within Europe, environmental monitoring is organized under EMEP, to which all nations contribute monitoring information in support of the overall modeling effort guiding the European emission control and regulation activities. Further collaboration is occurring among the acid deposition programs being conducted in North America and AMEP. Activities within MEDPOL, which is being carried out in collaboration with UNEP, are not as far advanced.

QASAC maintains strong relationships with research- or process-oriented programs, include them in QASAC planning, and have QASSAC included in their planning. (See Attachment I, IGOS-AG "The Ozone Project" Chapter 2 and Chapter 5.)

Besides the immediate need for training in operational matters, there is an urgent need to enhance scientific capacity and infrastructure in developing countries. IGAC's Atmospheric Chemistry and Environmental Education in Global Change $\left(A C E^{\mathrm{ED}}\right)$, the Global Change System for Analysis, Research, and Training (START), the Inter-American Institute for Global Change Research (IAI), and GAW have agreed to design and implement jointly a capacity-building program for atmospheric chemistry in developing countries. The initial emphasis is linked closely to the enhancement of the GAW global observatory network. The American Geophysical Union (AGU) in cooperation with the International Union of Pure and Applied Chemistry (IUPAC) has also recently established an international Volunteer Teaching Corps, which currently consists of about 150 members. The WMO--through the QA/SACs--will continue to assist this initiative and contribute to its implementation. This capacity-building program was first implemented as a pilot project in Argentina. Other activities took place in Chile and Brazil in 1997. 


\section{PROFILE OF QAVSAC ACTIVITIES.}

The QA/SAC at SUNY-ASRC is responsible for leading data quality assurance activities for stations of the Global Atmosphere Watch (GAW) located in North, Central, and South America. The specific aspects of this monitoring program relate to tropospheric ozone and those aspects of GAW monitoring for which the U.S. has accepted responsibility (particularly tropospheric ozone, UV-B radiation, precipitation chemistry and atmospheric aerosol optical depth).

- The QASAC at SUNY-ASRC generates appropriate quality control criteria and data verification and validation criteria applicable to the GAW field and laboratory measurements. These criteria will be examined and approved by scientific expert committees assembled for the purpose by the QA/SAC.

- The QAVSAC at SUNY-ASRC has set up and manages mechanisms to monitor data forwarded by site operators, and uses the data validation criteria mentioned above to identify data that are questionable.

- The QASAC at SUNY-ASRC applies data quality flags to information that fails to pass the validation test, and forwards such annotated data to the data archive/repository located at SUNY-ASRC's facility.

- The QASAC at SUNY-ASRC maintains contact with individual site operators, and communicates with them on a regular and routine basis as to the quality status of the data being generated by them.

- The QASSAC at SUNY-ASRC develops such training programs (capacity building) as may be needed to improve overall data quality.

- The QAVSAC at SUNY-ASRC conducts meetings, at least every two years, at which the results of the program are presented for outside peer review.

- The QAVSAC at SUNY-ASRC engages in independent scientific investigation of the data that are gathered, and presents the results of these investigations, as warranted, in the open scientific literature, with appropriate acknowledgement to WMO, GAW, and this program.

The past QA/SAC activities and accomplishments are further described in the following WMO publications:

\# 80 Report of the WMO Meeting of Experts on the Quality Assurance Plan for the GAW, Garmisch-Partenkirchen, Germany, 26-30 March 1992.

\# 83 Report on the Global Precipitation Chemistry Programme of BAPMON.

\# 85 Chemical Analysis of Precipitation for GAW: Laboratory Analytical Methods and Sample Collection Standards by Dr. Jaroslav Santroch.

\# 86 The Global Atmosphere Watch Guide, 1993.

\# 92 Report of the Second WMO Meeting of Experts on the Quality Assurance/Science Activity Centres of the Global Atmosphere Watch, Garmisch-Partenkirchen, 7-11 December 1992.

\# 93 Report of the Third WMO Meeting of Experts on the Quality Assurance/Science Activity Centres of the Global Atmosphere Watch, Garmisch-Partenkirchen, 5-9 July 1993.

\# 94 Report on the Measurements of Atmospheric Turbidity in BAPMoN.

\# 95 Report of the WMO Meeting of Experts on UV-B Measurements, Data Quality and Standardization of UV Indices, Les Diablerets, Switzerland, 25-28 July 1994. 
\# 97 Quality Assurance Project Plan (QAPjP) for Continuous Ground Based Ozone Measurements.

\# 98 Report of the WMO Meeting of Experts on Global Carbon Monoxide Measurements, Boulder, USA, 7-11 February 1994.

\# 99 Status of the WMO Global Atmosphere Watch Programme as at 31 December 1993.

\#100 Report of the Workshop on UV-B for the Americas, Buenos Aires, Argentina, 22-26 August 1994.

\#101 Report of the WMO Workshop on the Measurement of Atmospheric Optical Depth and Turbidity, Silver Spring, USA, 6-10 December 1993 (edited by Bruce Hicks).

\#102 Report of the Workshop on Precipitation Chemistry Laboratory Techniques, Hradec Kralove, Czech Republic, 17-21 October 1994.

\#103 Report of the Meeting of Experts on the WMO World Data Centres, Toronto, Canada, 1718 February 1995 (prepared by Edward Hare).

\#104 Report of the Fourth WMO Meeting of Experts on the Quality Assurance/Science Activity Centres (QAVSACs) of the Global Atmosphere Watch, jointly held with the First Meeting of the Coordinating Committees of IGAC-GLONET and IGAC-ACE, GarmischPartenkirchen, Germany, 13-17 March 1995.

\#105 Report of the Fourth Session of the EC Panel of Experts/CAS Working Group on Environmental Pollution and Atmospheric Chemistry (Garmisch, Germany, 6-11 march 1995).

\#107 Extended Abstracts of Papers Presented at the WMO-IGAC Conference on the Measurement and Assessment of Atmospheric Composition Change (Beijing, China, 9-14 October 1995).

\#110 Report of the WMO-NOAA Expert Meeting on GAW Data Acquisition and Archiving (Asheville NC USA, 4-8 November 1995).

\#111 Report of the WMO-BMBF Workshop on VOC Establishment of a "World Calibration/Instrument Intercomparison Facility for VOC" to Serve the WMO Global Atmosphere Watch (GAW) Programme (Garmisch-Partenkirchen, Germany, 17-21 December 1995).

\#113 GAW Strategic Plan.

\#114 Report of the Fifth WMO Meeting of Experts on the Quality Assurance/Science Activity Centres (QA/SACs) of the Global Atmosphere Watch, jointly held with the Second Meeting of the Coordinating Committees of IGAC-GLONET and IGAC-ACE ${ }^{\mathrm{ED}}$, GarmischPartenkirchen, Germany, 15-19 July 1996.

\#116 GAW Guide. 


\section{CONCLUSIONS.}

\section{Tropospheric Ozone.}

The performance of the SUNY QAVSAC has been exemplary. The activities separate into three convenient pieces.

Surface ozone. In this regard, new measurements are now being made in South America. The QAVAC led the process by which sites were identified and instrumentation selected. Now, the QAVSAC is setting up a quality control activity in Argentina to service the newly emerging "southern cone" data set.

Ozonesondes. The QA/SAC has succeeded in bring together previously divergent activities around the globe that have been confusing the interpretation of global ozone trends through their internal disagreements. A radiosonde intercomparison was arranged and conducted (at Julich, Germany). Major studies of ozonesonde performance are now being conducted, led by NASA and NOAA scientists.

Column ozone. The QASAC is actively starting to rationalize measurements programs involving Dobson and Brewer spectrophotometers. Dobson units form the basis for work conducted by NOAA. Brewer units are favored by the EPA. A recent disagreement about the way in which these devices were represented in international protocol presentations was adjudicated by the QAVSAC.

\section{Solar Radiation and Atmospheric Turbidity.}

The activity so far has been delayed by continuing debates about how to measure atmospheric turbidity. The designation of the Swiss as leaders of the aerosol optical depth development program has led to some considerable concern, since the developments of interest are now primarily those which are intended for global observatory application, as distinct from regional sites.

Interactions among the US solar radiation community and the international programs and data archives are now smoothly running.

\section{Ultraviolet Radiation.}

The QAVSAC has advocated the selection of the US Central UV Calibration Facility as an international point of reference. At present, the major obstacle relates to the availability of resources to permit the US facility to be employed.

A major disagreement among the international community, concerning the way in which spectral UV instrumentation is characterized and the protocols of data archiving has now been resolved. A formal WMO report was prepared.

\section{Precipitation Chemistry.}

This constitutes a major success of the endeavor. The US has responsibility for maintaining the global precipitation chemistry archive, and for assuring the quality of the data in it. The operation was in complete disarray before the QA/SAC started to assume the responsbility. Now, the operation is smoothly running, and the data archive is secure. The QA/SAC has been completely successful. This activity has been a major drain on time and resources of the QASAC. It has been anticipated that the effort involved will now decrease, and that new priorities (as above) will become dominant. In recent years, aerosols have become an increasing target for QAVAC attention.

\section{Management of Formal Quality Control Programs.}


The previous item (precipitation chemistry) is the best example so far of the successful implementation of an international formal QA process. The case of ozone (item 1 above) as a second example, although perhaps not yet as striking. The organization has a demonstrated track record that is quite impressive. They succeeded where the US EPA failed!

\section{International Recognition.}

The SUNY QAVSAC group has generated an enviable reputation among the international scientific community, and especially among air chemists. They are among the leaders of the international programs with which the QA/SAC work is allied.

\section{ACKNOWLEDGEMENTS.}

The work summarized here represents a concerted effort by three federal agencies to strengthen the program by which the health of the global atmosphere is monitored and assessed. The contributions by EPA, DOE and NOAA have succeeded in allowing an appropriately strong national response to the well perceived need to ensure that the global atmospheric climate is well documented, especially in locations where emerging economies are causing local environmental disruption that would otherwise not be included in the overall picture. 